\title{
Prognostic factors in the rehabilitation of patients with spinal problems
}

\author{
Alan E. Richardson \\ F.R.C.S. \\ ANNEMARIE D. TUPPER \\ M.B., B.S., D.Phys.Med. \\ Wolfson Medical Rehabilitation Centre, Atkinson Morley's Hospital, London
}

\begin{abstract}
Summary
One hundred patients undergoing intensive rehabilitation for painful spinal lesions were studied. They were divided into three groups in relation to result, these being 'good', 'moderate' or 'poor'. Seventy-eight per cent were regarded as 'good' or 'moderate'. The 'poor' group showed significantly raised neuroticism scores measured by the Middlesex Hospital Questionnaire, particularly sub-scores for 'depression' and 'somatic concomitants of anxiety' in women and 'free floating anxiety', 'depression' and 'obsessionality' in men. Other factors associated with poor outcome were long history, multiple operations and a nonspecific diagnosis of 'low back pain'. It is suggested that this group can be identified early and might benefit from a combined physical rehabilitation and psychotherapy programme. A controlled study to test this is planned.
\end{abstract}

\section{Introduction}

Over 2 million patients per year consult their general practitioner complaining of backache, resulting in the loss of thirteen and a half million working days. According to National Health Service certificates patients with lumbago remain off work for an average of 19 days, those with sciatica for 26 days, and those with prolapsed intervertebral discs for 56 days. Two per cent remain off work for 6 months (Wood, 1974).

The majority improve with appropriate treatment but some unpredictably respond poorly to any form of treatment. It is this 'failed treatment' group that has engaged the interest of a number of workers. White (1966) discussing low back pain in men receiving Workmen's Compensation commented that whereas $90 \%$ were disabled for less than 6 weeks, the remaining $10 \%$ constituted long term intractable problems not amenable to treatment. These made up one-third of the population of a 500-bedded Workmen's Compensational Hospital and Rehabilitation Centre in Canada.

It was suggested that this group might have some special characteristics which could be recognized and

Correspondence: Dr A. D. Tupper, The Wolfson Medical Rehabilitation Centre, Atkinson Morley's Hospital, Copse Hill, Wimbledon, London SW20 0NQ. possibly modified at an early stage of the patient's disability period.

Other workers (Carter, 1967; Dorfman, 1967; Minc, 1968) have discussed emotional and psychological factors associated with a poor response to treatment. In this study we assessed some of these factors using the Middlesex Hospital Questionnaire (MHQ). This is a short diagnostic self-rating scale consisting of forty-eight questions, each with two or three possible answers, one of which the patient selects. The total score measures neuroticism, the six sub-scores individually measure 'free floating anxiety' (A); phobic anxiety (P); obsessionality (O); somatic concomitants of anxiety (S); depression (D); and hysterical personality $(\mathrm{H})$ (Crown and Crisp, 1966). The MHQ has been validated on large numbers of normal and neurotic men and women (Crown, Duncan and Howell, 1970) of various ages (Cockett, 1969; Crisp and Priest, 1971) and has been used to assess the psychological status of patients with low back pain (Wolkind and Forrest, 1972) or treated with cardiac pacemakers (Crisp and Stonehill, 1969).

\section{Subjects}

One hundred patients with painful spinal symptoms referred for rehabilitation to the Wolfson Medical Rehabilitation Centre were included in the study, which extended over 3 years. Referrals were mainly from neurosurgeons and orthopaedic surgeons with a small number from physicians and general practitioners. There were sixty-two men and thirty-eight women. Ages ranged from 17 to 65 years with a mean age of 41.7 for men, and 41.4 for women. Of the total, $44 \%$ were in heavy work, the remaining $56 \%$ in light, or domestic employment. Diagnostically, 57\% had prolapsed intervertebral discs (PID), $15 \%$ were diagnosed as 'low back pain' (LBP), $12 \%$ were a miscellaneous group including patients with spondylolisthesis, arachnoiditis, spinal neurofibroma, traumatic subluxation and dysraphism, 9\% had cervical or lumbar spondylosis and $7 \%$ sciatica.

All had been treated previously elsewhere, frequently with several courses of different types of therapy. Eighty-three had been treated surgically at some time and fifty-seven were transferred early in the postoperative period. 


\section{Method}

On admission all patients were asked to complete the MHQ-one semi-literate patient refused and was excluded from the study. The questionnaires were filed unscored until the completion of the treatment and follow-up period.

Patients then took part in the usual rehabilitation programme. This consisted of six 40-min sessions daily for 5 days a week and included physiotherapy, hydrotherapy, remedial gymnastics and occupational therapy. Each patient's programme was individually arranged by the admitting medical officer and reviewed and increased at intervals according to progress.

Average stay in the Centre was 6.8 weeks but varied depending on the patient's progress and usual work.

On discharge, results were graded as 'good', 'moderate' or 'poor' and the grading was repeated by the same doctor after 3-6 months. Follow-up was carried out either in the clinic or by means of a simple questionnaire.

Outcome was considered to be 'good' if the patient was pain-free, or nearly so, his activities unrestricted and he had returned to his former occupation; 'moderate' if the patient was pleased with the result and working, but either had to limit his activities or complained of more than occasional mild pain. Also included in this group were patients who returned to full activity, but continued on regular medication (analgesics and/or tranquillizers). The 'poor' results group consisted of patients who felt their disability to be unimproved, whose activities were markedly restricted, who had not returned to work or needed readmission for further treatment during the follow-up period. Whenever there was a discrepancy between discharge and follow-up result the patient was graded in the less favourable results group; this occurred only rarely.

Finally, the MHQs were scored and the scores of the 'good' and 'poor' outcome group compared using the Mann-Whitney ' $U$ ' test (Smart, 1963).

Other factors considered in relation to outcome were age, occupation, chronicity, diagnostic category and previous surgery.

The number of patients involved in compensation cases in this series was too small for separate comparison.

\section{Results}

From Table 1 it can be seen that $78 \%$ of the whole group did well or moderately well.

\section{$M H Q$}

Figures 1 and 2 show the MHQ profiles of the 'good', 'moderate' and 'poor' groups together with the 'normal' profile for the appropriate sex and age.
TABLE 1. Results of rehabilitation

\begin{tabular}{lcccr}
\hline & Total & Good & Moderate & Poor \\
\hline Men & 62 & 29 & 24 & 9 \\
Women & 38 & 16 & 9 & 13 \\
& 100 & 45 & 33 & 22 \\
\hline
\end{tabular}

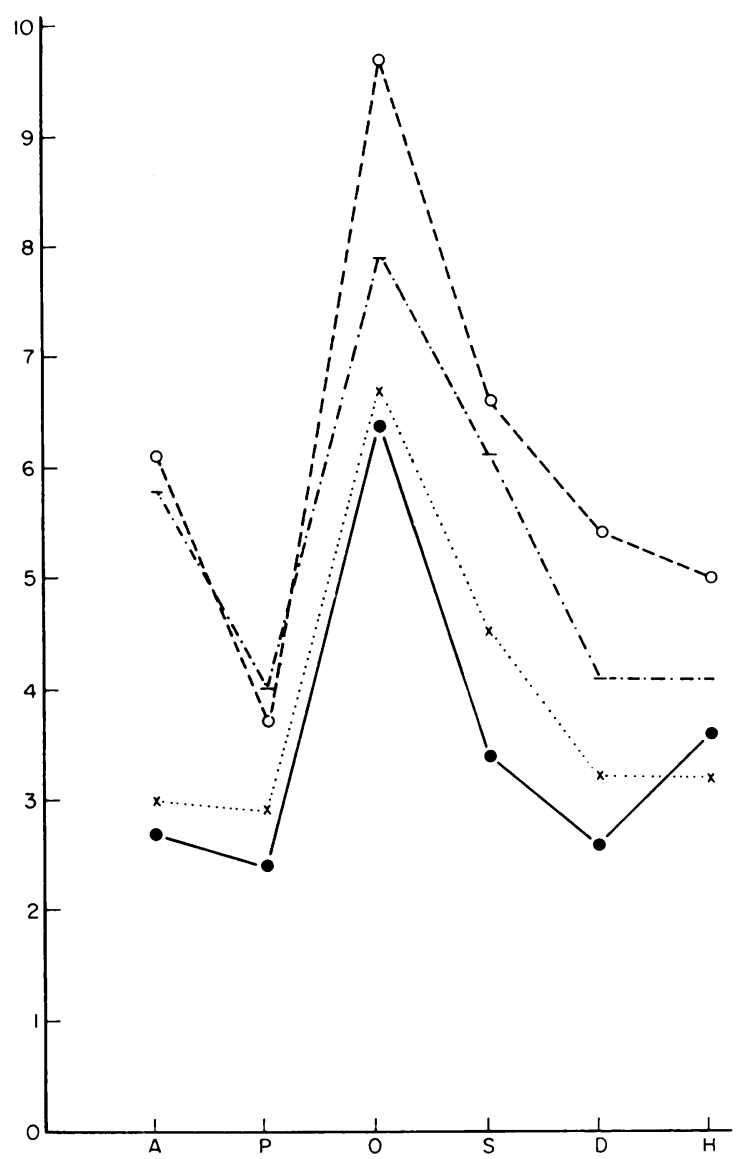

FIG. 1. Mean MHQ profile of male patients. Normal (age 40-44 years), solid line; good, dotted line; moderate, dotted and dashed line; poor, dashed line.

On both diagrams the profile of the 'good outcome' group is almost identical with the 'normal'. Scores for the 'poor' group are highest and the 'moderate outcome' group is mid-way between the two. It was decided to compare the scores of the 'good' with that of the 'poor' group using the Mann-Whitney U test (Smart, 1963).

The total score difference in men is significant between $P 0.01$ and 0.001 , and the total score difference in women is significant at $P$ 0.05. Subscore ' $A$ ' (free floating anxiety) is significant at $P 0.02$ in men, and not significant in women; subscore ' $O$ ' (obsessionality) is significant between $P 0.02$ and 


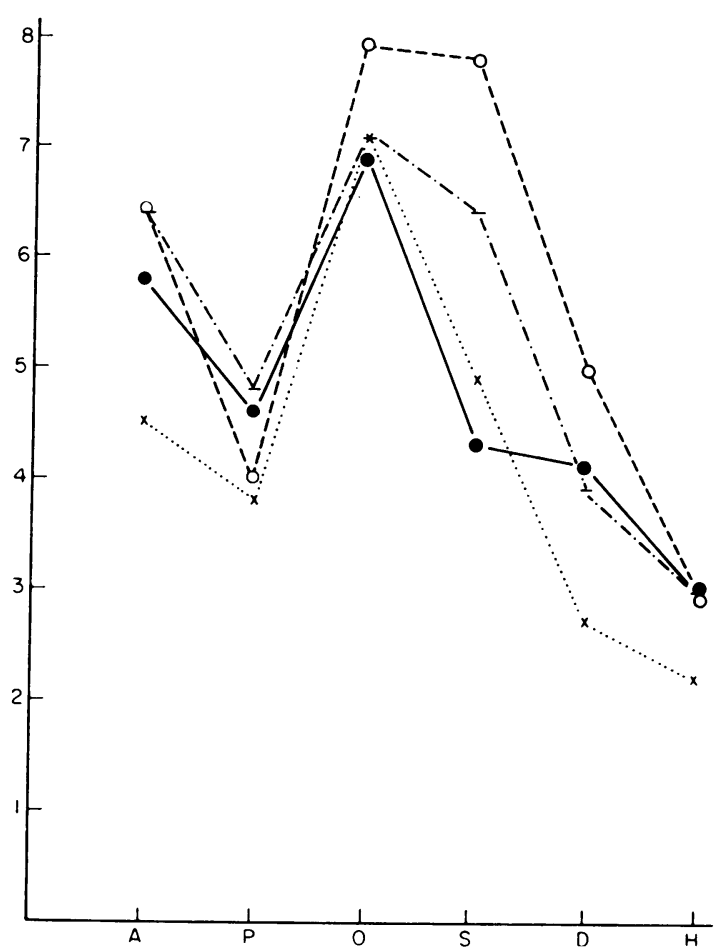

FIG. 2. Mean MHQ profile of female patients. Normal, (age 40-44 years), solid line; good, dotted line; moderate, dotted and dashed line; poor, dashed line.

0.05 in men, and not significant in women; subscore ' $D$ ' (depression) is significant at $P$ 0.02 in men, and at $\boldsymbol{P} 0.01$ in women; subscore ' $\mathrm{S}$ ' (somatic concomitants of anxiety) is not significant in men, and significant at $P \quad 0.025$ in women; subscore 'P' (phobic anxiety) and ' $H$ ' (hysterical personality) showed no significant difference in either sex.

\section{Age (Table 2)}

The difference between mean age of all males (41.7) and all females (41.4) was not significant. The low mean age in the 'poor' male group is probably due to the small size of this group, which included four very young patients. The greater mean age in the 'poor' female group is similar to the figures of Wolkind and Forrest (1972) who found the mean age in their 'good' group to be 35.1 years, that of the 'poor' group 43.6. According to Wood (1973) the peak age for patients with back pain is

TABLE 2. Mean age in relation to outcome

\begin{tabular}{lccc}
\hline & Good & Moderate & Poor \\
\hline Mean age & & & \\
Men & $42 \cdot 8$ & 43.6 & $33 \cdot 2$ \\
Women & $36 \cdot 1$ & 44.0 & $46 \cdot 1$ \\
\hline
\end{tabular}

44 years. White (1966) found no significant difference in age between 'satisfactory' and 'unsatisfactory' patients.

\section{Occupation}

Forty-four per cent of patients were employed on heavy manual labour such as carpentry, engineering and grave digging. Housewives with young families were also included in this heavy physical demand group. Fifty-six per cent were employed in light industrial, clerical, managerial or professional work, or were housewives with grown-up families. The proportion of heavy workers was higher $(54 \%)$ in the moderate outcome male group and lower in the good and poor female groups $(37 \%$ and $31 \%$ respectively).

\section{Diagnosis (Table 3)}

Of the fifty-seven patients with definite disc prolapse forty-six fared well or moderately well and eleven gave poor results. Of seven patients with sciatica five did well, or moderately well and two badly; almost $50 \%$ (seven of fifteen) of the patients with low back pain responded poorly. Out of twentyone patients in the miscellaneous and spondylitic group only two failed to improve.

TABLE 3. Distribution of diagnoses in outcome groups

\begin{tabular}{lrcccc}
\hline & PID & Sciatica & LBP & Spondyl. & Misc. \\
\hline $\begin{array}{l}\text { Good } \\
\text { Men }\end{array}$ & 18 & 1 & 3 & 5 & 2 \\
$\quad$ Women & 13 & 2 & - & - & 1 \\
$\begin{array}{l}\text { Moderate } \\
\quad \text { Men }\end{array}$ & 12 & 1 & 5 & 2 & 4 \\
$\quad$ Women & 3 & 1 & - & 1 & 4 \\
$\begin{array}{l}\text { Poor } \\
\text { Men }\end{array}$ & 5 & - & 3 & - & 1 \\
$\quad$ Women & 6 & 2 & 4 & 1 & - \\
$\begin{array}{l}\text { Total no. } \\
\text { patients }(\%)\end{array}$ & 57 & 7 & 15 & 9 & 12 \\
\hline
\end{tabular}

\section{Duration of symptoms (Table 4)}

In both sexes the duration of symptoms was longer in the 'poor' groups and these patients had undergone various forms of treatment without adequate improvement before their admission to the Centre. To assess whether chronicity was associated with

TABLE 4. Duration of symptoms

\begin{tabular}{|c|c|c|c|c|c|}
\hline & Mean & Range & $\begin{array}{c}<1 \\
\text { year }\end{array}$ & $\begin{array}{c}<5 \\
\text { years }\end{array}$ & $\begin{array}{c}>5 \\
\text { years }\end{array}$ \\
\hline \multicolumn{6}{|l|}{ Good } \\
\hline Men & $4 \cdot 8$ & $2 / 12-22$ years & 9 & 11 & 8 \\
\hline Women & $4 \cdot 2$ & $2 / 12-11$ years & 4 & 7 & 5 \\
\hline \multicolumn{6}{|l|}{ Poor } \\
\hline Men & $7 \cdot 8$ & $1 / 12-32$ years & 2 & 4 & 3 \\
\hline Women & 11.9 & $2-34$ years & 0 & 3 & 10 \\
\hline
\end{tabular}


high MHQ scores patients with less than 5 years' duration of symptoms were compared with those of more than 5 years in the same outcome group. No significant difference was found in total MHQ or subscores.

\section{Surgery (Table 5)}

Eighty-three per cent of patients had one or more operations, fifty-seven of them shortly before admission. Seventeen per cent had been treated conservatively. In the 'good outcome' group thirty-five of forty-five patients had one operation (usually laminectomy), two further patients had two and three operations respectively, and eight had none. Of the twenty-two patients in the 'poor outcome' group $33 \%$ (seven) had had multiple operations (repeat laminectomies, explorations or fusions), one of them four; only three had been treated conservatively.

TABLE 5. Number of operations

\begin{tabular}{lccc}
\hline & $\begin{array}{c}\text { No } \\
\text { surgery }\end{array}$ & $\begin{array}{c}\text { One } \\
\text { operation }\end{array}$ & $\begin{array}{c}\text { Multiple } \\
\text { operations }\end{array}$ \\
\hline Good & 8 & 35 & 2 \\
Moderate & 6 & 19 & 8 \\
Poor & 3 & 12 & 7 \\
& 17 & 66 & 17 \\
\hline
\end{tabular}

\section{Discussion}

Features associated with 'poor outcome' under our treatment regime were found to be vague diagnosis such as LBP, multiple surgery and a long history. It is suggested that a patient with a 'vague diagnosis' may be given vague, non-specific treatment which does not relieve his symptoms so that he is likely to be seen with a long past history.

Overall, $78 \%$ of our patients showed good or moderate results. This is considerably higher than the improvement rate of $54 \%$ in the series of Wolkind and Forrest (1972), who studied fifty men treated with six sessions of physiotherapy over the course of 3 weeks, excluding all patients with proven PIDs, $\mathrm{X}$-ray abnormalities or neurological signs. This limits their series to patients with 'lumbo-sacral strain' and LBP, a group which did relatively badly in our series. Our figure of $48 \%$ poor results in this LBP group is very close to the $46 \%$ of Wolkind and Forrest (1972) and the $51 \%$ of White (1966). The only difference noted in the MHQ scores of the LBP group compared with the rest was an obsessionality score in men marginally higher than was warranted by the outcome grading of the patients in this group. Male and female patients with poor outcome showed a higher total score, in particular subscores for depression (D), somatic concomitants of anxiety (S) in women and depression (D), anxiety (A) and obsessionality $(O)$ in men. These differences are not accountable for in terms of diagnosis or multiple operations. It is not clear why the ' $O$ ' score should be significantly raised in men but not in women except possibly for the fact that the normal female ' $O$ ' score is higher than the male in the fourth and fifth decade.

The high ' $A$ ' score in men faring badly may be associated with economic anxiety, particularly where physical strength is considered essential for earning power and backache has connotations of prolonged disability. This is contrary to Wolkind and Forrest (1972) who found no difference in ' $A$ ', ' $P$ ' and ' $H$ ' scores between the good and poor outcome group, but found a highly significant difference in ' $S$ ' and less significant difference in ' $D$ ' and ' $O$ ' scores.

White (1966), on the contrary, in an analysis of fourteen personal factors including physical, mental and environmental, showed none to be helpful in predicting results of treatment in workmen receiving compensation for LBP.

Similarly, Partridge et al. (1968) in a survey of rheumatic complaints including lumbar pain in foundry workers, found little difference in matched pairs using the Maudsley Scale of 'extroversion' and 'neuroticism'. He did find, however, that the patients complaining of 'rheumatic symptoms' tended to have greater sickness absence from other complaints and were also complaining of a greater number of symptoms at time of interview. This may correspond to the increased ' $S$ ' score found in our series in the 'poor' outcome group.

Lopez Ibor Alino (1971) stresses the diagnostic value of the failure of somatic treatment to relieve symptoms-so does Thornton Brown et al. (1954) in discussing psychological factors in LBP, and Carter (1967) who found in his extensive clinical experience that the pain 'is continuous, completely unrelieved by analgesics, varies according to the patient's interests at the time and often seems to disappear conveniently when the patient has something pleasant to do'. That the high depressive scores cannot be ignored is supported by Lopez Ibor Alino (1971) who mentions sciatica and lumbago occurring as depressive equivalents particularly in younger people with excessive anxiety. In his experience, these symptoms may occur before, after or instead of, a severe depression, but do not coincide.

This might explain why many of the 'poor outcome' group patients are not noted to be seriously depressed, but do not make progress with the usual physical treatment regime.

Levine (1971) suggests a mechanism relating depression to disc disorders. In depressed patients alterations in corticosteroid metabolism increase intracellular sodium (Coppen, 1969). This causes increased sodium content of disc material followed by disc swelling and pressure on nerve roots, giving 
rise to neurological signs and symptoms and leading to further depression due to backache. Some support is given to this theory by experiments of Scott (1955) who exposed voles to regular stress experiences and found the size of the nucleus relative to the total disc area to be significantly increased when compared with unstressed litter mates.

Stevenson (1970) discussing whiplash injuries mentions a depressive reaction as a primary result of injury in an anxious individual rather than as a result of failure of treatment and persistent pain.

Without a prospective study of a populatian at risk it is difficult to make any statements whether pain follows or precedes depression, but it is likely that at some stage a vicious cycle of pain $\longrightarrow$ depression $\longrightarrow$ more pain leading to further depression is established and this is most likely to occur in anxious individuals. The MHQ measures current psychological status rather than basic personality traits, and without full psychiatric investigation it is not possible to be certain whether a patient has been abnormally depressed, anxious or obsessional before the onset of his backache. The rise in ' $D$ ' score in normals with advancing middle age may be significant in relation to poor outcome in older patients with longer history. As suggested by other workers (Levine, 1971; Stevenson, 1970; Thornton Brown et al., 1954), combined physical and psychiatric treatment might give better results in a selected group of patients with back problems. Our results make it likely that this group could be identified by means of the MHQ. It is hoped to carry out a controlled trial of intensive rehabilitation, psycho-therapy and a combination of both types of treatment in an appropriate group of patients-preferably at an early stage of their illness.

\section{Acknowledgments}

We are most grateful to Professor Crisp of St George's Hospital for helpful discussions regarding the MHQ and we should like to thank the patients and nursing staff of the Wolfson Centre for their willing co-operation.

\section{References}

CARTer, A.B. (1967) The functional overlay. Lancet, ii, 1196.

Cocketr, R. (1969) A short diagnostic self-rating scale in the pre-adult remand setting. British Journal of Psychiatry, $115,1141$.

Coppen, A. (1969) Disorders of mineral metabolism in depressive patients. Psychiatria, Neurologia, Neurochirurgia, 72, 189.

Crisp, A.H. \& Stonehill, E. (1969) Aspects of the psychological status of patients treated with cardiac pacemakers. Postgraduate Medical Journal, 45, 423.

CrisP, A.H. \& Priest, R.G. (1971) Psychoneurotic profiles in middle age. British Journal of Psychiatry, 119, 385.

Crown, S. \& CRISP, A.H. (1966) A short clinical diagnostic self-rating scale for psychoneurotic patients. British Journal of Psychiatry, 112, 917.

Crown, S., DunCaN, K.P. \& Howell, R.W. (1970) Further evaluation of the Middlesex Hospital Questionnaire. British Journal of Psychiatry, 116, 33.

Dorfman, W. (1971) 5th World Congress of Psychiatry (Mexico City) 1971. Excerpta Medica, 662.

LEVINE, M.E. (1971) Depression, back pain and disc protrusion. Diseases of the Nervous System, 32, 41.

LOPEZ IbOR Alino, J.J. (1971) 5th World Congress of Psychiatry (Mexico City). Excerpta Medica, 644.

Minc, S. (1968) Psychological aspects of backache. The Medical Journal of Australia, 1, 964.

Partridge, R.E.M., Anderson, J.A.D., MCCARThy, M.A. \& DuthIE, J.J.R. (1968) Rheumatic complaints among workers in iron foundries. Annals of the Rheumatic Diseases, 27, 441 .

Scotr, J.C. (1955) Stress factors in the disc syndrome. The Journal of Bone and Joint Surgery, 37B, 107.

SMART, J.V. (1963) Elements of Medical Statistics. Second edition. Staples Press: London.

Stevenson, H.G. (1970) Back injury and depression-a medico legal problem. Medical Journal of Australia, 23, 1300.

Thornton Brown, T., Nemiah, J.C., Barr, J.S. \& Barry, H., JR (1954) Psychological factors in low back pain. New England Journal of Medicine, 251, 123.

WHITE, A.W.M. (1966) Low back pain in men receiving workmen's compensation. Canadian Medical Association Journal, 95, 50.

Wolkind, S.N. \& ForRest, A.J. (1972) Low back pain: a psychiatric investigation. Postgraduate Medical Journal, 48, 76.

Wood, P.H.M. (1973) Private Communication.

WooD, P.H.M. (1974) Statistical digest of the Arthritis and Rheumatism Council Epidemiology Research Unit. Annals of the Rheumatic Diseases, 33, 93. 